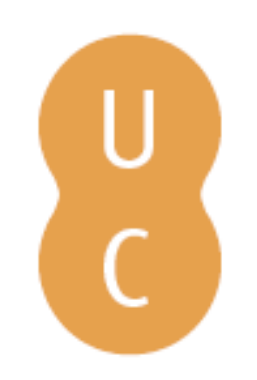

\title{
nombalina
}

\section{Mario Vargas Llosa e o escândalo interminável de Fedra}

Autor(es): $\quad$ López, Aurora; Pociña, Andrés

Publicado por: Centro de Estudos Clássicos e Humanísticos da Universidade de

URL

persistente: URI:http://hdl.handle.net/10316.2/30115

DOI: $\quad$ DOI:http://dx.doi.org/10.14195/978-989-721-010-5_12

Accessed : $\quad$ 26-Apr-2023 12:42:47

A navegação consulta e descarregamento dos títulos inseridos nas Bibliotecas Digitais UC Digitalis, UC Pombalina e UC Impactum, pressupõem a aceitação plena e sem reservas dos Termos e Condições de Uso destas Bibliotecas Digitais, disponíveis em https://digitalis.uc.pt/pt-pt/termos.

Conforme exposto nos referidos Termos e Condições de Uso, o descarregamento de títulos de acesso restrito requer uma licença válida de autorização devendo o utilizador aceder ao(s) documento(s) a partir de um endereço de IP da instituição detentora da supramencionada licença.

Ao utilizador é apenas permitido o descarregamento para uso pessoal, pelo que o emprego do(s) título(s) descarregado(s) para outro fim, designadamente comercial, carece de autorização do respetivo autor ou editor da obra.

Na medida em que todas as obras da UC Digitalis se encontram protegidas pelo Código do Direito de Autor e Direitos Conexos e demais legislação aplicável, toda a cópia, parcial ou total, deste documento, nos casos em que é legalmente admitida, deverá conter ou fazer-se acompanhar por este aviso.

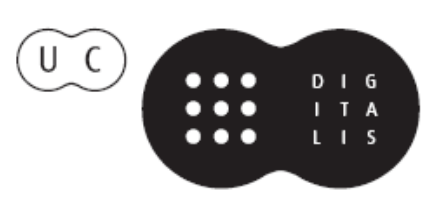




\section{Hipólito e Fedra}

\section{nos caminhos de um mito}

Carlos A. Martins de Jesus, Claudio Castro Filho, José Ribeiro Ferreira (coords.) 


\title{
Mario Vargas Llosa e o escândalo interminável de Fedra
}

\author{
Aurora López, Andrés Pociña \\ Universidade de Granada
}

\section{Um prémio Nobel e uma coincidência}

Quando no dia 7 de outubro de 2010 irrompeu em todos os meios de comunicação a notícia da concessão do Prémio Nobel de Literatura do ano ao romancista de nacionalidade peruana e espanhola Mario Vargas Llosa (n. Arequipa, Peru, 1936), tínhamos em estado bastante avançado a elaboração deste trabalho, que respondia a um velho projeto, destacado de um estudo, de nossa autoria, de entre os muitos contidos no livro Fedras de ayer y de hoy, editado por ambos faz agora dois anos". Com efeito, depois de nos ocuparmos da "madrasta apaixonada" que aparece no livro X de O Burro de Ouro de Apuleio, acrescentámos este breve parágrafo sobre o tratamento do mesmo tema numa obra que nos é próxima no tempo: "Cuando, después de un número crecido de Fedras en el teatro, la poesía, la novelística, el cine, la escultura, la pintura, llegamos, en el año 1988, a la novela erótica de Mario Vargas Llosa, Elogio de la madrastra ${ }^{2}$, en la que doña Rigoberta, la madrastra, es quien resulta seducida por el perverso Fonchito, su hijastro, casi uno niño, para luego eliminarla de su vida culpándola a ella ante su padre de lo ocurrido, llegamos a una revisión total, casi imposible de llevar más lejos, de las revisiones profundas iniciadas ya por el propio Eurípides en sus dos versiones de Hipólito" (A. Pociña, A. López 2008: 284-285)3.

Surpreende-nos a coincidência entre a concessão do universalmente reconhecido prémio a Vargas Llosa e a nossa remissão ao estudo da sua obra

${ }^{1}$ Concretamente no trabalho de A. Pociña 2008: 269-285.

2 M. Vargas Llosa 1988, ${ }^{5} 2002$. Uma aproximação a este romance desde a perspetiva da tradição clássica pode ler-se em M. E. Assis de Rojo, N. M. Flawiá de Fernández (1998), "Fedra y Narciso en Elogio de la madrastra de Mario Vargas Llosa", em Textos clásicos, reescrituras contemporáneas, San Miguel de Tucumán: 87-99. Dada a novidade do assunto, reproduzimos a interessante nota que, a propósito deste romance, intruduzem G. Fiorencis e G. F. Gianotti, "Fedra e Ippolito in província", cit. p. 107, n. 100: "Cenno a parte meriterebbe, per raffinata e originale miscela di erotismo e mitologia, la recente 'riabilitazione' della matrigna tentata da Mario Vargas Llosa nell'Elogio de la madrastra (1988; tr. it., Rizzoli 1990): riabilitazione solo parziale negli esiti della storia, perché anche nel lontano Perù Fedra/Lucrecia finisce per essere cacciata, dopo aver assaporato una singolare sovranità su padre e figlio; riabilitazione vera, tuttavia, rispetto al palinsesto mitico, perché l'iniziativa del traingolo spetta, poco convenzionalmente, all'inquietante e non proprio innocente espansività fisica del figliastro adolescente (incarnazione di un Cupido luciferino, piuttosto che di un casto Ippolito)”.

${ }^{3}$ A nota precedente encontra-se no original do texto citado; consideramos oportuno repetila, dado que nela citávamos os únicos dois trabalhos por nós conhecidos que se ocupavam da obra estudada de Vargas Llosa. 
desde a perspetiva das suas fontes clássicas. Estamos conscientes de que, na produção literária do ficcionista, ocupam um posto de maior relevo romances mais famosos como, por exemplo, La ciudad y los perros (1963), Conversación en La Catedral (1970), Pantaleón y las visitadoras (1973), La tía Julia y el escribidor (1977) ou La fiesta del Chivo (2000), entre muitos outros; não obstante, o muito menos conhecido romance erótico Elogio de la madrastra coaduna em nossa opinião o duplo interesse de ser, como dizíamos, "una revisión total, casi imposible de llevar más lejos" do tema clássico de Fedra, e de ser uma obra em que se manifesta, em maior grau que em qualquer outra do escritor, o influxo notável de um conhecimento profundo da literatura e da cultura greco-romanas.

\section{Os escândalos de Fedra}

A primeira versão teatral que conservamos completa do tema de Fedra e Hipólito deve-se a um escândalo: trata-se, é óbvio, da tragédia Hipólito de Eurípides, que obteve o primeiro prémio na sua estreia, no ano de 428 a.C., dados que lemos no argumento do gramático Aristófanes de Bizâncio editado antes da obra, ele que assinala, além disso, que "o drama é dos melhores" do tragediógrafo; mas acrescenta também: trata-se do segundo Hipólito, em que corrigia "o que havia de inconveniente e merecedor de censura" de uma tragédia anterior. Os factos são bem conhecidos, e repetem-se uma e outra vez, até à exaustão, sempre que se fala do Hipólito de Eurípides; tanto assim é que não é tarefa fácil pôr uma nota bibliográfica respeitante a este assunto. Para resumirmos da forma mais breve possível, diremos que Eurípides compôs uma primeira versão, o chamado Hipólito velado ( $\kappa \alpha \lambda u \pi \tau o ́ \mu \varepsilon v o \varsigma)$, assim designado porque Hipólito cobria a cabeça para ocultar a vergonha que lhe produzia a ousada e impudica declaração amorosa da madrasta. Quando a tragédia foi representada, provavelmente em 432 a.C., o público, escandalizado pelo excesso imoral de Fedra ao declarar a sua paixão pelo filho do marido, repudiou a obra. Pouquíssimos anos depois ${ }^{4}$, Eurípides acusava a receção da crítica enviada pelo público escandalizado, levando à cena o Hipólito que conservamos, chamado Hipólito o da coroa ( $\sigma \tau \varepsilon \varphi \alpha v i ́ \alpha \varsigma)$, ou Hipólito portador da coroa ( $\sigma \tau \varepsilon \varphi \alpha \nu \eta \varphi o ́ \rho \circ \varsigma)$, em que Fedra ostentava um comportamento muito mais assumível do ponto de vista moral, preocupada em ocultar a sua paixão,

\footnotetext{
${ }^{4}$ Não esqueçamos que, entre as duas composições do Hipólito de Eurípides, é quase seguro que tenhamos de colocar a estreia da Fedra de Sófocles (ainda que nem toda a crítica esteja de acordo com esta colocação de uma tragédia perdida). Cf., a este propósito, de forma especial, J.V. Bañuls, P. Crespo 2008: 31: "En Sófocles al componer su Fedra - y dejamos por ahora a un lado la cuestión de la datación - debió influir el ambiente generado en Atenas por la Fedra euripidea, pero lejos de verse mediatizado por él, debió contribuir a enriquecer a su personaje, a su Fedra, a esto hay que añadir la expectación que debió provocar entre los atenienses el que Sófocles fuese a llevar al teatro una tragedia sobre Fedra e Hipólito".
} 
que de nenhum modo se atreve a declarar ao enteado; uma paixão que, por outro lado, é desculpável por ser atribuída à ação de uma divindade, a deusa Afrodite, irritada contra Hipólito, que se apresenta no Prólogo (vv. 1-57) 5 . A nova versão, já o recordámos, ganhou o concurso do ano da sua estreia.

O tema em que se centra Eurípides na segunda versão, sem dúvida de maneira menos ousada do que na primeira, resultava, de todas as formas, escandaloso para o seu tempo, e ainda para o nosso, vinte e cinco séculos depois. Nele se conjugam a figura de uma mulher tomada pela paixão e irrefreavelmente apaixonada; uma mulher apaixonada, aliás, por um rapaz supostamente menor de idade e isento de experiência erótica; uma mulher apaixonada, sobretudo, por um jovem que é seu enteado. Resulta, pois, um exemplo perfeito e cabal do antiprotótipo de mulher, esposa e mãe, sendo pelo contrário o perfeito exemplo da madrasta, dentro da tipologia conhecida como "madrasta apaixonada".

Devemos a Patricia A. Watson (1995) um amplíssimo estudo sobre a condição das madrastas no mundo greco-romano, analisando-as desde perspetivas literárias, históricas e sociológicas, explorando o que é o retrato do estereótipo da madrasta no mito e na literatura, em comparação com a vida real. Estabelece Watson três variantes literárias: (a) a madrasta assassina; (b) a madrasta perseguidora da sua enteada; (c) a madrasta apaixonada ${ }^{6}$. O tipo mais frequente na literatura grega e latina é o primeiro, ainda que aqui enfrentemos um caso correspondente ao terceiro. Nas palavras da mesma investigadora, “o tratamento da madrasta 'apaixonada' ostenta não apenas uma disposição favorável à geração mais jovem, como também um prejuizo misógino contra a madrasta, proveniente de atitudes masculinas gregas relativas à sexualidade das mulheres" (P. A. Watson 1995: 216).

O escândalo da estreia do primeiro Hipólito deve ter tido uma grande repercussão em Atenas; os seus ecos chegaram ao nosso tempo através das comédias de Aristófanes, segundo estudou com grande minúcia e correção M. F. S. Silva 2008: 1077; um parágrafo seu põe bem em relevo as causas que teriam provocado o escândalo:

${ }^{5}$ A diferença essencial que existe entre a intervenção da divindade - refletida pela presença em concreto das deusas Afrodite (no Prólogo) e Ártemis (no Êxodo) - no Hipólito de Eurípides e sua ausência na Fedra de Séneca foi estudada com toda precisão por G. Petrone 2008: 239-250.

${ }^{6}$ P. A. Watson 1995: 208: “The literary stereotype of the stepmother takes three main forms: (1) the stepmother as murderess, her motivation being to obtain the inheritance for her own son, (2) the stepmother as persecutor of a stepdaughter, (3) the 'amorous' stepmother".

${ }^{7} \mathrm{O}$ tema da mulher que se apaixona por um homem mais jovem volta a aparecer, dentro da obra de Eurípides, em Os Cretenses, Fénix e provavelmente em Peleu. Por sua vez, Estenebeia, a mulher de Preto, rei de Tirinte, ao ver-se descartada por Belerofonte, jovem hóspede da corte do seu marido, acaba por denunciá-lo como seu sedutor. Cf. a reconstituição da peça levada a cabo por T. B. L. Webster (1967), The Tragedies of Euripides. London: 80-84. 
¿Qué era, pues, lo que vinculaba, desde la perspectiva de la comedia, las Fedras con las Estenebeas y Melanipas, transformándolas en modelo de libertinaje? Todas ellas violan el código moral normalmente aceptado para la condición femenina. Sometidas a una pasión devoradora, ponen en peligro su honra y sus deberes familiares, cuando se determinan a adentrarse por caminos osados buscando conquistar al hombre que aman. Decepcionadas o traicionadas, son capaces de todo, hasta el punto de dejar sembrada a su alrededor incluso la muerte a la que ellas mismas se habían condenado. En este aspecto, Fedra y Estenebea comparten un destino semejante; casadas, ambas han concebido por un joven un amor adúltero y al no verse correspondidas, denuncian, ante sus maridos, al amante renitente, atribuyéndole un intento de violación.

No caso da Fedra de Séneca, tão diferente do Hipólito de Eurípides que se conservou, há razões de peso, nas quais não podemos entrar aqui, para pensar que coincidia em mais de um aspeto com a tragédia perdida do grego, a que originou o escândalo. Não podemos já, neste caso, falar de um escândalo, porque é sabido que não possuímos em absoluto dados sobre possíveis representações das tragédias de Séneca na Antiguidade, nem tampouco sobre sua receção em datas próximas à sua redação. De qualquer modo, a rutura escandalosa do comportamento moralmente admissível de uma mulher, de que se gabava a Fedra de Séneca na apaixonada declaração amorosa ao enteado, está fora de questão, conforme estudámos há já alguns anos (cf. A. López 1997: 281-289; Idem 2008: 251-267).

Dando um salto de pouco mais de dezesseis séculos, de novo rebenta um "escândalo Fedra", desta vez na Paris dos tempos de Luis XIV: o escândalo consiste na estreia, com apenas dois dias de diferença, de duas tragédias sobre Fedra, escritas por dois dramaturgos que se enfrentam nos âmbitos social e literário, Jean Racine y Jacques Pradon. Este escândalo foi estudado em pormenor por Aurora López (2008: 323-335), de onde tomamos este resumo dos factos (idem: 325): “Todos estos enfrentamientos están en la base de la querella de las dos Fedras que se estrenan con sólo dos días de diferencia. Phèdre et Hippolyte de Racine se lleva a las tablas un viernes, el día 1 de enero de 1677, en el Hôtel de Bourgogne ${ }^{8}$. Dos días después, Pradon estrena Phèdre et Hippolyte en el Hôtel Génégaud. La rivalidad se declara manifiesta en el hecho mismo de tan seguidos estrenos".

Três séculos mais tarde, agora na Espanha dos momentos mais angustiantes da ditadura franquista, será possível motivo de escândalo a tragédia convertida em cinema, a Fedra do realizador Manuel Mur Oti, estreada em 1956, com

\footnotetext{
${ }^{8}$ Pouco tempo depois, em 1687, aparece já com o título de Phèdre, com que a conhecerá a posteridade.
} 
Emma Penella no papel de Estrella (Fedra), Vicente Parra no de Fernando (Hipólito), Enrique Diosdado no de D. Juan (Teseu). O filme - neste volume reapreciado por Nuno Simões Rodrigues - foi objeto de um excelente trabalho de Francisco Salvador Ventura (2008: 503-524)' , que põe em destaque o caráter transgressor da obra no tempo em que foi representada, com uma Fedra de aspeto, comportamento e palavra absolutamente fora do admissível no cinema daqueles anos, coisa que surpreende igualmente na apresentação de Hipólito, em que o muito popular ator Vicente Parra aparece com um chamativo cabelo loiro e uma indumentária claramente sugestiva de uma postura homossexual, num momento político em que a homossexualidade era considerada um delito grave. Apesar de tudo, e para surpresa nossa, a obra conseguiu estrear; ainda assim, a censura obrigou previamente o realizador a mudar o final, em que Fedra se suicidava, afogando-se no mar depois de beijar a boca de Hipólito já morto. Persiste a dúvida sobre como foi possível que semelhante filme não tenha sucumbido ao rigor inquisitorial do franquismo, já que o facto de se tratar de uma obra de inspiração clássica, baseada na Fedra de Séneca, não parece argumento suficiente.

\section{O escândalo de Elogio de la madrastra de MarioVargas Llosa}

Não nos consta que o romance Elogio de la madrastra de Mario Vargas Llosa tenha causado um escândalo público importante, ainda que tampouco nos estranhasse que assim tivesse sido. Antes nos escandaliza, de maneira positiva, o facto de o prémio Nobel ter escrito um romance tão diferente do resto de sua produção narrativa, um romance erótico no sentido mais amplo da palavra, a partir de um tema clássico, os amores da madrasta Fedra, porém reconvertido de uma forma absoluta, sem precedentes: é aí que descobrimos o escândalo, digamos agora que surpreendente, como surpreendente é a profunda cultura clássica greco-latina que se aprecia com subtileza e elegância pelas páginas do livro.

Elogio de la madrastra apareceu em 1988 em La Sonrisa Vertical, coleção de literatura erótica dirigida pelo ilustre realizador de cinema Luis García Berlanga, a quem Vargas Llosa dedica o romance, "con cariño y admiración”. O relato articula-se em catorze capítulos e um epílogo, incluindo, além do mais, seis reproduções a cores de quadros, mais ou menos conhecidos, indispensáveis por estarem incluídas as suas descrições no desenvolvimento do conjunto; nisso reside uma das novidades interessantes da obra, que chama à atenção pela sua originalidade narrativa.

$\mathrm{O}$ assunto consiste numa reescrita profunda do tema clássico de Fedra e Hipólito, em nossa opinião baseada essencialmente na Fedra de Séneca, mas

\footnotetext{
${ }^{9}$ Vd. também R. M. Mariño Sánchez-Elvira 1997: 113-115.
} 
possivelmente também em elaborações posteriores, como a Phèdre de Racine ou a Fedra de Unamuno, sem esquecer os filmes de Manuel Mur Oti e Jules Dassin - os quais, quase seguramente, Vargas Llosa conhecia quando escreveu a obra, sobretudo o segundo. Recordaremos as linhas do argumento, a partir das personagens, em relação com as das duas tragédias clássicas.

Começamos por dom Rigoberto, o marido da madrasta, reencarnação do Teseu antigo, e assim o fazemos porque no romance esta personagem ocupa um posto realmente importante, ao contrário do que ocorria nas duas tragédias clássicas, nas quais aparecia numa altura já muito avançada do desenvolvimento: no Hipólito de Eurípides, no terceiro episódio, verso 790, onde se apresentava regressado do oráculo; na Fedra de Séneca, ao começo do ato III, verso 835, onde anunciava seu regresso dos Infernos. dom Rigoberto, por sua vez, está sempre presente no romance, embora faça algumas viagens curtas, de dois ou três dias, que também interessam ao desenrolar do argumento; é um agente de seguros, divorciado, com um filho pequeno; leva uma vida economicamente muito cómoda, com uma elegante casa, de dois andares e um jardim, em Lima, onde habitam o filho Alfonsito, mais comumente chamado pelo diminutivo afetuoso Fonchito, a nova mulher, dona Lucrecia, e uma nutrida equipa de serviço doméstico, com cozinheira, jardineiro e, sobretudo, uma donzela, Justiniana, a quem Fonchito chama Justita, que desempenha um papel também importante, como veremos. Tudo muito organizado, tudo muito burguês, porém tudo nada normal, porque dom Rigoberto é, à sua maneira, émulo do sempre agitado Teseu da mitologia ${ }^{10}$ : boa parte do relato narra-nos, com toda a calma e insinuante lascívia, o cuidado que dom Rigoberto, autêntico Narciso, dedica todos os dias indefetivelmente ao seu corpo, antes de ir deitar-se com a sua nova mulher. Testemunha um pequeno parágrafo: "Hoy era martes, día de pies. Tenía la semana distribuida en órganos y miembros: lunes, manos; miércoles, orejas; jueves, nariz; viernes cabellos; sábado ojos y, domingo, piel. Era el elemento variable del noturno ritual, lo que le confería un aire cambiante y reformista"(M. Vargas Llosa 1988, ${ }^{5}$ 2002: 86). Deste modo, dom Rigoberto, na aparência um acomodado agente de seguros, está possuído por uma infatigável fixação erótica, concentrada em todos os órgãos de seu corpo, que Vargas Llosa nos dá a conhecer ao longo de capítulos inteiros, como no terceiro, intitulado "Las orejas del miércoles", ou no sexto, "Las abluciones de don Rigoberto", em que nos vemos condenados a conhecer em pormenor o prazer diário dos alívios intestinais do personagem. Em suma, um indivíduo um tanto perturbado sexualmente, no qual atuam simultaneamente um onanismo-narcisismo na

${ }^{10}$ Uma apresentação das múltiplas peripécias e aventuras deste personagem mitológico pode ser vista no amplo tratamento que lhe atribui P. Grimal (1965), Diccionario de las mitologías griega y romana, pp. 505-510. Trad. Francisco Payarols. Barcelona. 
adoração do próprio corpo, um indubitável voyeurismo que manifesta ao comparar a mulher com a esposa do rei Candaules, uma ânsia de animalismo quando quer comparar-se a um monstro, reflexo óbvio do Minotauro. Este Teseu limenho, de erotismo insaciável, está loucamente apaixonado por dona Lucrecia, com quem mantém todas as tardes relações sem dúvida satisfatórias.

Dona Lucrecia é uma esplêndida mulher de 40 anos, nova Fedra, menos no desenlace do romance, que se debate continuamente entre a imortalidade e a inconveniência do, sem dúvida, assédio sexual, por mais que tencione ignorá-lo, a que submete o menino, para cúmulo seu enteado, e o indubitável prazer que progressivamente vai experimentando à medida que essa relação pedófila se desenvolve, até atingir a plenitude. Ao que parece, e por oposição ao que acontecia nas tragédias grega e romana de Fedra, dona Lucrecia é vítima do assédio de Fonchito, quer dizer, subvertem-se os comportamentos de Fedra e Hipólito; porém, na realidade, as coisas passam-se de outro modo, pois dona Lucrecia engana-se desde o início, trata de interpretar as bajulações, as carícias, os beijos, os toques a que a submete Fonchito como travessuras de um inocente menino, coisa que evidentemente não é assim. Por mais que reflita, na tentativa de ocultar de si própria a verdade da relação, com um sentimento de culpa que, livre da seriedade trágica, nos recorda o que assola a Fedra cristã de Unamuno (cf. A. Pociña 1999: 299-325), os seus sentidos traem-na: ao começar o relato, a donzela Justiniana adverte-a de que, quando toma banho, o enteado Fonchito a contempla, montado sobre o telhado de cristal; não obstante, numa ocasião em que sabe que o menino está a vê-la, reage deste modo: "La cólera la hacía temblar de pies a cabeza y sus dientes chocaban, como si tuviera mucho frío. Súbitamente se incorporó. Sin cubrirse con la toalla, sin encogerse para que aquellos ojitos invisibles tuvieran sólo una visión incompleta y fugaz de su cuerpo. No, al revés. Se incorporó empinándose, abriéndose, y, antes de salir de la bañera, se desperezó, mostrándose con largueza y obscenidad, mientras se sacaba el gorro de plástico y se sacudía los cabellos. Y, al salir de la bañera, en vez de ponerse de inmediato la bata, permaneció desnuda, el cuerpo brillando con gotitas de agua, tirante, audaz, colérico" (M. Vargas Llosa 1988, ${ }^{5} 2002$ : 63) ${ }^{11}$. Mais adiante, quando a relação com o menino já é plena, dona Lucrecia continua a brincar com a ideia de que se trata de um menino, o que não absolve a perversidade da relação, social e moralmente considerada um caso óbvio de pedofilia e adultério, não de incesto.

${ }^{11}$ Esta cena do banho é seguida pela reprodução do famoso quadro de François Boucher, "Diana depois do banho" (Museu do Louvre, Paris), que se explica no capítulo 5 do romance, onde Diana e sua acompanhante se transformam em dona Lucrecia e sua donzela Justiniana, que mostram sem rodeios que conhecem muito bem a natureza erótica das relações entre a madrasta e Fonchito. 
Alfonsito, aliás Fonchito, apresenta grandes diferenças em comparação com o Hipólito trágico. Em primeiro lugar, não é um jovem, nem sequer um efebo, qualquer que seja a idade ou o modo de representar o enteado de Fedra, senão claramente um menino, cuja idade não se precisa, mas que colocaríamos em torno dos dez anos, ou até um pouco menos. Um menino, pois, que como tal se comporta em todos os aspetos da sua vida, a não ser no sexual, onde se mostra verdadeiramente precoce, e no psíquico, onde se mostra um autêntico monstro de maldade. Frente ao que acabamos de afirmar, Fonchito, pequeno, formoso, de feições bondosas, apresenta-se a cada instante como um verdadeiro anjo: deste modo nos é descrito ao começar o relato, quando a madrasta vai despedir-se dele antes de dormir: "Doña Lucrecia tocó con los nudillos y entró: ‘Alfonsito!'. En el cono amarillento que irradiaba la lamparilla del velador, de detrás de un libro de Alejandro Dumas, asomó, asustada, una carita de Niño Jesús. Los bucles dorados revueltos, la boca entreabierta por la sorpresa mostrando la doble hilera de blanquísimos dientes, los grandes ojos azules desorbitados tratando de rescatarla de la sombra del umbral. Doña Lucrecia permanecía inmóvil, observándolo con ternura. ¡Qué bonito niño! Un ángel de nacimiento, uno de los pajes de los grabados galantes que su marido escondía bajo cuatro llaves" (M. Vargas Llosa 1988, ${ }^{5}$ 2002: 16 sqq.). Um menino Jesus, um anjinho de Belém... que, com as suas travessuras, carícias e beijos, faz com que a madrasta, quando abandona o dormitório, depois de cobri-lo ternamente, se confesse sexualmente acesa ${ }^{12}$. O papel que desempenhará nas malhas do argumento não deve ser objeto da nossa exposição: Fonchito conquistará o favor, o apaixonado e ardente favor, podemos dizer, da madrasta, ao longo do relato, até que, no final, põe em prática o seu projeto inicial, que consiste em desfazer-se por completo dela. A “inocente" maquinação que põe em marcha consiste em perguntar ao pai, quando este regressa de uma curta viagem (nova coincidência com as tragédias clássicas), o que significa a palavra "orgasmo", que terá escutado de dona Lucrecia. Dom Rigoberto, atónito na sua suspeita inacreditável, pede ao menino que o deixe ler uma composição de tema livre que deve levar à escola, ficando alucinado com a história erótica que na sua redação conta o angelical menino, "Elogio de la madrastra", que não nos é transmitida no texto, mas que, damo-nos conta, torna dona Lucrecia a culpada

${ }^{12} \mathrm{O}$ menino muito pequeno que representa Eros/Amor no quadro de Ticiano "Venus com o Amor e a Música”, do Museu do Prado, que se explicará no capítulo 7, no momento em que dom Rigoberto acaba os cuidados corporais que lhe servem de preâmbulo e estímulo para as relações com dona Lucrecia - "Hoy no será Lucrecia sino Venus y hoy pasarás de peruana a italiana y de terrestre a diosa y símbolo" (M. Vargas Llosa 1988, ${ }^{5} 2002$ : 103) -, não corresponde à idade de Fonchito, que por força há de ser um menino de mais anos, já mais desenvolvido, porém de modo algum um adolescente, pois que nos é dito que "acaba de hacer su primera comunión" (M. Vargas Llosa 1988, ${ }^{5}$ 2002: 53). 
de tudo quanto aconteceu. $\mathrm{O}$ recurso da redação de Fonchito, assim como a sua visão particular do assunto, corresponde perfeitamente ao da tabuinha que Fedra deixa escrita ao suicidar-se, no Hipólito de Eurípides, por meio da qual Teseu conhece a sua versão particular das relações com Hipólito (vv. 856 sqq.).

Tampouco resulta menos importante o papel que desempenha no romance a personagem de Justiniana, que evidentemente evoca o da Ama nas tragédias clássicas, e de modo acentuado o da Ama no drama de Séneca (cf. A. López 2008: 251-267), na sua função de conselheira de dona Lucrecia, ainda que nem sempre boa conselheira. Quando revela à senhora as sessões de voyeurismo a que a submete Fonchito durante o banho, é-nos apresentada deste modo: "Era joven y, bajo el mandil azul del uniforme, las formas de su cuerpecillo se insinuaban frescas y elásticas. ¿Qué cara pondría cuando su marido le hacía el amor? Estaba casada con el portero de un restaurante, un negro alto y fornido como un atleta que venía a dejarla todas las mañanas. Doña Lucrecia le había aconsejado que no se complicara la vida con hijos siendo tan joven y la había llevado personalmente a su médico para que le recetara la píldora"(M. Vargas Llosa 1988, ${ }^{5}$ 2002: 56). No Epílogo do romance, as últimas palavras de Fonchito, entre carícias e beijos à donzela, que tinha recriminado o seu mau comportamento para com a madrasta, advertem-nos para uma nova reviravolta na vida desta peculiar família, na qual ninguém está a salvo de uma terrível servidão erótica: "- Lo hice por ti, Justita - lo oyó susurrar, con aterciopelada ternura -, no por mi mamá. Para que se fuera de esta casa y nos quedáramos solitos mi papá, yo y tú. Porque yo a ti... / La muchacha sintió que, sorpresivamente, la boca del niño se aplastaba contra la suya” (M. Vargas Llosa 1988, ${ }^{5}$ 2002: 197).

Parece óbvio que Mario Vargas Llosa, na sua reescrita do tema clássico da madrasta apaixonada, subverte por completo os papéis, a um nível que não tínhamos observado na quase uma centena de versões do tema de Fedra e Hipólito que conhecemos diretamente. Não vamos entrar numa crítica do resultado, pois não nos parece lógica nem necessária, nem cremos ter cabimento dar lugar a comentários pessoais que não devem ser objeto do estudo literário rigoroso. Ainda assim, queremos sublinhar, como já antecipámos, de que maneira a cultura clássica greco-latina impregna com subtileza as páginas do romance. Vejamos três passagens que o demonstram de maneira fidedigna.

A primeira é o capítulo 9, "Semblanza de humano". Precedido pelo óleo "Cabeza I" (1948) de Francis Bacon, uma cabeça monstruosa, serve este semblante de resposta à fantasia erótica com que acaba dom Rigoberto o capítulo anterior, no qual sugere à mulher que acaba de fazer amor com um monstro. A uma pessoa não habituada à leitura dos clássicos pareceria que, entre as várias perturbações sexuais de dom Rigoberto, se encontraria esta repugnante cena de animalismo. Não obstante, não há dúvida que Vargas 
Llosa, numa profunda leitura dos clássicos, reparou na obsessão que preocupa Fedra, sobretudo a de Séneca, de que o seu amor é monstruoso, como outros amores que acometeram membros da sua linhagem, como o amor monstruoso do Minotauro. O tema desta obsessão de Fedra, precisamente a de Séneca, foi estudado, com enorme precisão e pormenor, por Gianna Petrone (2008: 239-250), que o considera essencial na configuração da personalidade da protagonista no drama do filósofo ${ }^{13}$; é um aspeto em que concordamos com a latinista de Palermo quando afirmamos o seguinte: "En contra de ese ambiente vital propio de una mujer prototípica, Fedra evoca una existencia en espacios libres, montes, selvas (vv. 122 sqq.), que traen a su mente la imagen de su madre, Pasífae, y su amor monstruoso con el toro. Sus antecedentes familiares no hacen más que reforzar la culpa de su amor, un amor fatal, heredado de su madre y por decreto divino: "ninguna hija de Minos ha gozado / de un amor sencillo, siempre se le une una monstruosidad", dice Fedra (vv. 127 sqq.). Un poco antes, Fedra interpela a su madre, a propósito de su relación con el toro: audax amasti (v. 117), unas palabras que hubiera podido aplicarse a sí misma cuando llega a la osadía de declararse a Hipólito. Madre e hija resultan audaces como consecuencia de sus amores irregulares y se despreocupan de comportarse en consonancia con la pudicitia que la sociedad les impone. En ese sentido el amor de Fedra lleva implícito un nefas" (A. López 2008: 259 sqq.). Parece claro que o capítulo sobre o monstro que mantém uma relação com um humano foi sugerido a Vargas Llosa por essa presença constante do Minotauro na mente angustiada da protagonista da Fedra de Séneca.

O segundo passo que queremos comentar, devido ao seu influxo clássico, é o segundo capítulo do romance, encabeçado pela reprodução do quadro de Jacob Jordaens, "Candaules, rei da Lídia, exibe a mulher ao ministro Giges", um óleo de 1648, conservado no Museu Nacional de Estocolmo. O relato de Giges e Candaules, peça destacada da literatura erótica e essencial no tema do voyeurismo, aparece muito bem colocado no romance, depois de uma das primeiras fantasias de dom Rigoberto, que imagina que a sua mulher

${ }^{13}$ Desse autor veja-se, por exemplo, este acertado e preciso parágrafo (p. 240): "Lungamente evocato a più riprese, il fratello animale di Fedra testimonia la perversione erotica della madre e della parentela femminile, rivelando nel suo stesso essere le conseguenze terribili della violazione delle leggi regolatrici dell'universo. Questa ossessiva presenza del Minotauro, il cui ricordo perseguita Fedra come un orrore 'familiare' ed è usato come deterrente dalla nutrice, ad un certo punto si trasforma da fantasma della mente in una sorta di doppio reale. Infatti il mostro marino, mezzo toro e mezzo pesce, che sollevandosi dal mare, in seguito alla maledizione di Teseo, causa la morte di Ippolito, non può non ricollegarsi al Minotauro, la cui spaventosa ambiguità riproduce. L'incubo della creatura indefinibile partorita da Pasifae in qualche modo si rinnova in un nuovo mostro, evocato da Teseo, ma generato in ultima analisi dall'amore fuori dalle regole di Fedra. Dietro Fedra, c'è infatti costantemente, secondo l'interpretazione senecana, la madre Pasifae, il cui modo abominevole d'amare segna la figlia come una condanna e una coazione a ripetere. La protagonista assomiglia troppo alla propria madre e lo sa”. 
poderia ser a bela esposa do rei da Lídia, antes de assistirmos às repetidas cenas de voyeurismo que protagonizará Fonchito, ao contemplar do telhado de cristal a madrasta nua no banho. É sabido que o mais antigo relato da história de Candaules, rei da Lídia, e do desgraçado final a que o conduziu a louca paixão pela esposa, que a todo custo se empenha em ser vista nua por Giges, se encontra magistral e deliciosamente narrado no começo do livro I das Histórias de Heródoto (caps. 6-14). Vargas Llosa, que segue Heródoto ao ponto de reproduzir com exatidão o nome do pai de Giges, reescreve o conto a seu gosto, aumentando muito o seu grau de erotismo, em especial no momento em que o rei Candaules se diverte com a mulher, sabendo que Giges os está a observar. $\mathrm{E}$ depois, de acordo com a conveniência do romance, interrompe o relato no momento em que Giges contemplou a rainha nua, sem chegar ao desenlace narrado por Heródoto, com a vergonha dessa mulher, que se alia a Giges para dar morte a Candaules. Vale a pena uma leitura comparada do relato de Heródoto com o tremendamente obsceno de Vargas Llosa.

Por fim, a terceira passagem que queríamos comentar: chegados já ao capítulo 11 do romance, quando a madrasta tem relações sexuais completas com Fonchito, assistimos a um momento em que dona Lucrecia fica a sós com ele, completamente nu, depois de consumado o sexo. Contemplando-o, pensa dona Lucrecia: "Así debían de ser los dioses griegos. (...) Los amorcillos de los cuadros, los pajes de las princesas, los geniecillos de Las mil y una noches, los

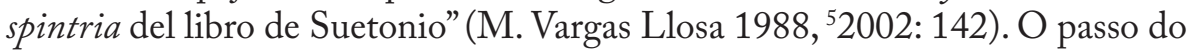
biógrafo latino é facilmente detetável, porquanto apenas emprega este termo uma vez ${ }^{14}$ : trata-se, diz-nos Suetónio, do nome obviamente grego que dava Tibério aos que participavam nos seus bacanais. Vale a pena recordar o texto de Suetónio, tão semelhante a muitos de Elogio de la madastra; fa-lo-emos na versão espanhola de Mariano Bassols de Climent: "En su retiro de Capri ideó incluso una sala provista de divanes, escenario de sus pasiones secretas, a fin de que en ella pandillas de muchachas y de mozos de placer, reclutados de todas partes, así como inventores de monstruosos ayuntamientos, a los que llamaba spintrias, enlazados de tres en tres, se prostituyeran recíprocamente en su presencia para reanimar, con este espetáculo, su líbido que languidecía” ${ }^{15}$. Nibil nouum sub sole, teria dito Terêncio.

${ }^{14}$ Vargas Llosa, pelo contrário, repeti-lo-á pouco depois, na página 146.

${ }^{15}$ Suet., Tib. 43: Secessu uero Caprensi etiam sellaria excogitauit, sedem arcanarum libidinum, in quam undique conquisiti puellarum et exoletorum greges monstrosique concubitus repertores, quos spintrias appellabat, triplici serie conexi, in uicem incestarent coram ipso, ut aspectu deficientis libidines excitaret (C. Suetonio Tranquilo, Vida de los doce Césares, texto revisado e traduzido por Mariano Bassols de Climent, vol. II, Barcelona, Alma Mater, 1968). 